\title{
Interventional Study for Improving Health Information System in Khyber Pakhtunkhwa, Pakistan
}

\author{
Rab Nawaz $^{1}$, Shahzad Ali Khan ${ }^{2}$, Tayyaba Khattak ${ }^{1}$, Fatima Nasir ${ }^{1}$, Kiran Abbas ${ }^{3}, 4$ \\ 1. Community Medicine, Pak International Medical College, Peshawar, PAK 2. Public Health, Health Services Academy, \\ Islamabad, PAK 3. Medicine, Jinnah Postgraduate Medical Centre, Karachi, PAK 4. Medicine and Surgery, Sindh Medical \\ College, Karachi, PAK
}

Corresponding author: Kiran Abbas, kiranabbas2020@gmail.com

\section{Abstract \\ Objective}

To assess the improvement in the health information system in the district Nowshera by integrating the data reporting of the Expanded Program on Immunization (EPI) and Lady Health Worker (LHW) programs in the existing system.

\section{Methodology}

The study was conducted at district Nowshera and Swabi, Pakistan between May 2015 and May 2016 for a duration of one year. The data collection instruments used in the study were adapted from the Performance of Routine Information System Management (PRISM) tool package. The study was conducted in three phases during a period of one year. The first three months were utilized for baseline assessment. The next six months were being used for implementing the integration of the EPI and LHW, and the next three months were being used for the post-intervention evaluation. Microsoft Excel software was used to enter and analyze the data. A $\mathrm{p}<0.05$ was considered as the cut-off value for significance.

\section{Results}

The results indicated that the integration of data from the EPI and LHW with that of the existing Health Information System (HIS) is possible and has the potential for improving the existing system. The least significant results were produced by the use of information, which depicts that the utilization of data in decision making or policy making is still needed to be improved. Moreover, we reported a lack of enforcement and regulation by the authorities in monitoring the feedback system in the HIS.

\section{Conclusion}

Review began 10/08/2020 Review ended 11/19/2020 Published 11/30/2020

\section{() Copyright 2020}

Nawaz et al. This is an open access article distributed under the terms of the Creative Commons Attribution License CC-BY 4.0., which permits unrestricted use, distribution, and reproduction in any medium, provided the original author and source are credited.
The current study revealed significant improvements in the use of information, data quality, and behavior of staff. It is essential to properly train the team on how to operate the District Health Information System (DHIS) to gain adequate and timely data on health status and determinants. Additionally, the integration would benefit in managing the data at not only the national level but at the district level too.

Categories: Medical Education, Public Health, Healthcare Technology

Keywords: district health information system, prism, use of information, world health organization, pakistan, khyber pakhtunkhwa, healthcare system

\section{Introduction}

The health information system (HIS) provides reliable, authentic, and timely information on the health status of a region and aids in analyzing large amounts of data in summarized forms, which further guides the policymakers to improve upon the healthcare system [1-2]. HIS helps the policymakers to detect issues and make evidence-based decisions on health policies and programs; hence, improving the healthcare system [3].

HIS is one of the essential core elements of a healthcare system, as described by the WHO framework [4]. A reliable and trustworthy information system gives the pivot to make decisions about the structure of health organizations at any level. However, discrepancies and untimely information in the HIS system may render the system useless, further deteriorating the overall healthcare situation in any country [5].

One of the frameworks, called Performance of Routine Information System Management (PRISM), is being utilized for improving the health information system, worldwide [6]. PRISM comprises an applied system and related information assortment and scrutiny apparatuses to survey, plan, reinforce, and assess HIS. The 
PRISM system can be utilized for evaluating HIS execution, procedures, and its major components, specialized and social elements [7].

The structure of HIS in Pakistan is not integrated at the sub-district, district, provincial and national levels; instead, it is in the form of fragments with multiple vertical systems operating individually. The Health Management Information System (HMIS) was set up by the government of Pakistan in 1992 [8]. Later in 2004 and 2007, an improved system called the District Health Information System (DHIS) was established in collaboration with the United Nations Population Fund (UNFPA) [9]. The implementation was made sure through the National action plan. DHIS protocol was implemented throughout the country in a phase-wise process effected from 2005. However, despite the recent developments, there is still a critical need to improve the health information system in the health sector of the country in general and Khyber Pakhtunkhwa in specific. Hence, the current study aims to evaluate a modified conceptual framework, PRISM, to assess routine health information systems in two districts of Khyber Pakhtunkhwa. Additionally, the authors studied the impact of the integration of the data reporting of the Expanded Program on Immunization (EPI) and Lady Health Worker (LHW) programs with the health information system in district Nowshera of Khyber Pakhtunkhwa.

\section{Materials And Methods}

The present interventional study was conducted from June 2015 to June 2016 in two districts i.e., district Nowshera and Swabi of Khyber Pakhtunkhwa. The study was conducted in three phases. The first three months were utilized for baseline assessment of DHIS. The next six months were used for implementing the integration of the EPI and LHW program altogether in a single information system of DHIS. Finally, the post-intervention assessment was conducted.

The functioning of the Provincial District Health Information (DHIS) Cell, Districts Health Offices, and Health Facilities and the health staff involved in the process of health information systems were analyzed and recorded. Furthermore, the study recruited data to learn the impact of the integration. For evaluating the effects of integration, the two districts Nowshera and Swabi were selected. Swabi district, where the DHIS system was well-established, was kept as the control. The data collection instruments used in this study were adapted from the PRISM tool package that was modified for this study [10]. This tool package addresses the utilization of routine health information system (RHIS) data that is collected within the oneyear range from the health facilities [2].

The following data collection tools (questionnaires) were adopted for assessment of the health information system in district Nowshera and district Swabi (see the Appendix):

Organizational and Behavioral Assessment Tool (OBAT)

DHIS Diagnostic Tool Health Facility Proforma: Quality of Data

DHIS Diagnostic Tool Health Facility Proforma: Use of Information

The data regarding DHIS performance, the efficacy of the managers and their subordinates, the use of DHIS data by the district office, and supervision by the district health office were assessed using the abovementioned questionnaires. The intervention of integration was carried out in the district Nowshera while the Swabi served as a control district. The two districts share similar sociodemographics [11]. The total number of health facilities being operational in Nowshera was 33 at the time of the study conducted. Out of these 33 facilities, 13 facilities were selected randomly. Besides evaluating the technical capabilities of the district, the culture of using the health information system for assessing the progress of the health system is also evaluated. For that purpose, a set of questions were prepared according to the score of which the acceptability of using the DHIS was analyzed. The study population was categorized into two major groups, the administrative units included the district/health facilities and the second group included the employees that managed the health information systems. All the primary and secondary level health facilities in the public sector were involved in the process of integration.

After baseline evaluation, the health staff of the health information system was trained in data collection and timely reporting. Intervention (intervention in the shape of an integrated form of the process of data collection and timely reporting) was conducted in district Nowshera. After six months of the interventional approach, findings were compared with district Swabi. The process of data collection was carried out through various stakeholders. As described earlier, the PRISM package consists of three inbuilt tools: Use of information, quality of data, and Organizational \& Behavioral Assessment Tool (OBAT). SPSS version 26 (IBM Corp., Armonk, NY) was used to enter and analyze data. Chi-square test and Mann-Whitney-U were used to analyze the pre- and post-intervention data. A p-value of less than 0.05 was considered statistically significant.

\section{Results}




\section{Cureus}

In the pre-intervention period, all three tools produced non-significant results. However, after intervention and integration of EPI and LHW programs, we found significant improvements in DHIS, Nowshera with respect to compilation of the reports containing the DHIS data and in receiving the feedback report from the DHO office. In displaying the information about the health of the mother, child, and disease surveillance again we got significant results. After the integration of DHIS in the Nowshera district, the significant results could also be seen in the decision-making process while using the information obtained from the Nowshera's facilities. A significant change was also marked in the behavior of the district health officer as he started visiting the facilities in three or six months. The record-keeping, the maintenance of the record, and using that record in making the decision and setting the health targets showed a significant response (Table 1 ).

\begin{tabular}{|c|c|c|c|c|c|c|}
\hline \multicolumn{2}{|l|}{ Query } & \multicolumn{2}{|c|}{$\begin{array}{l}\text { Nowshera } \\
\text { (n\%) }\end{array}$} & \multicolumn{2}{|c|}{ Swabi (n\%) } & $\begin{array}{l}\text { p- } \\
\text { value }\end{array}$ \\
\hline \multirow{2}{*}{ Does this facility compile DHIS Data? } & Yes & 24 & $80.00 \%$ & 12 & $40.00 \%$ & \multirow{2}{*}{0.002} \\
\hline & No & 6 & $20.00 \%$ & 18 & $60.00 \%$ & \\
\hline \multirow{2}{*}{ Does the facility compile any report containing DHIS information? } & Yes & 20 & $66.67 \%$ & 8 & $26.67 \%$ & \multirow{2}{*}{0.002} \\
\hline & No & 10 & $33.33 \%$ & 22 & $73.33 \%$ & \\
\hline \multirow{2}{*}{$\begin{array}{l}\text { Did the facility receive any feedback from the district office on their performance for the last three } \\
\text { months? }\end{array}$} & Yes & 6 & $20.00 \%$ & 0 & $0.00 \%$ & \multirow{2}{*}{0.010} \\
\hline & No & 24 & $80.00 \%$ & 30 & $100.00 \%$ & \\
\hline \multicolumn{7}{|l|}{ Display of Information } \\
\hline \multicolumn{7}{|l|}{ Does the district office display the following data: } \\
\hline \multirow{2}{*}{ Mother Health } & Yes & 18 & $60.00 \%$ & 0 & $0.00 \%$ & \multirow{2}{*}{0.000} \\
\hline & No & 12 & $40.00 \%$ & 30 & $100.00 \%$ & \\
\hline \multirow{2}{*}{ Child Health } & Yes & 16 & $53.33 \%$ & 3 & $10.00 \%$ & \multirow{2}{*}{0.000} \\
\hline & No & 14 & $46.67 \%$ & 27 & $90.00 \%$ & \\
\hline \multirow{2}{*}{ Facility Utilization } & Yes & 13 & $43.33 \%$ & 2 & $6.67 \%$ & \multirow{2}{*}{0.001} \\
\hline & No & 17 & $56.67 \%$ & 28 & $93.33 \%$ & \\
\hline \multirow{2}{*}{ Disease Surveillance } & Yes & 22 & $73.33 \%$ & 5 & $16.67 \%$ & \multirow[b]{2}{*}{0.000} \\
\hline & No & 8 & $26.67 \%$ & 25 & $83.33 \%$ & \\
\hline \multirow{2}{*}{ Does the office have a map of the catchment area? } & Yes & 10 & $33.33 \%$ & 2 & $6.67 \%$ & 0.010 \\
\hline & No & 20 & $66.67 \%$ & 28 & $93.33 \%$ & \\
\hline \multirow{2}{*}{ The office displays a summary of demographic information: } & Yes & 12 & $40.00 \%$ & 1 & $3.33 \%$ & 0.001 \\
\hline & No & 18 & $60.00 \%$ & 29 & $96.67 \%$ & \\
\hline \multirow{2}{*}{ Any feedback (quarterly, yearly) report on DHIS data } & Yes & 10 & $33.33 \%$ & 0 & $0.00 \%$ & 0.001 \\
\hline & No & 20 & $66.67 \%$ & 30 & $100.00 \%$ & \\
\hline \multicolumn{7}{|l|}{ If yes, what kinds of decisions are made in reports of DHIS data/information? } \\
\hline \multirow{2}{*}{ Review strategy by examining actual performance on a month to month comparisons } & Yes & 8 & $80.00 \%$ & - & - & - \\
\hline & No & 2 & $20.00 \%$ & - & - & - \\
\hline \multirow{2}{*}{ Review facility personnel responsibilities by examining service performance } & Yes & 3 & $30.00 \%$ & - & - & - \\
\hline & No & 7 & $70.00 \%$ & - & - & - \\
\hline \multirow{2}{*}{ Mobilization/shifting of resources based on the comparison by services } & Yes & 2 & $20.00 \%$ & - & - & - \\
\hline & No & 8 & $80.00 \%$ & - & - & - \\
\hline \multirow{2}{*}{ Advocacy for more resources by comparing performance by targets } & Yes & 6 & $60.00 \%$ & - & - & - \\
\hline & No & 4 & $40.00 \%$ & - & - & - \\
\hline
\end{tabular}




\section{Cureus}

Discussion and Decision on DHIS information

Does the facility have routine meetings for reviewing managerial matters?

How frequently is the meeting supposed to take place?

How many times did the meeting take place during the last three months?

Is an official record of management meetings maintained?

If yes, please check the meeting records for the last three months:

Management of DHIS, such as data quality, reporting, or timeliness of reporting

Discussion on DHIS findings such as disease data, or service coverage, medicine

Have they made any decisions based on the above discussions?

Any follow-up action taken on the decisions made during the previous meetings?

Any DHIS related issues/problems referred to at the provincial level for actions?

Use of Information by the District Office

Facility received annual/monthly planned targets based on DHIS information?

Did records of the facility of the last three months show that district directives?

Did the facility receive the district DHIS office newsletter/report in the last three months?

Does any documentation exist to show us information?

Did the person in charge of the facility participate in meetings at the district level to discuss DHIS performance for the last three months?

Examples of how the facility uses DHIS information for health system management

Facility received annual/monthly planned targets based on DHIS information

Supervision by the district health office

Did the district supervisor visit your facility during the last three months?

Did you observe the supervisor having a checklist to assess the data quality?

Did the supervisor check the data quality?

Yes $16 \quad 53.33 \% \quad 4 \quad 13.33 \%$

$3 \quad 3$

21

Yes $\quad 13 \quad 81.25 \% \quad 2 \quad 50.00 \%$

0.001

$\begin{array}{lllllll}\text { Yes } & 13 & 100.00 \% & 2 & 100.00 \% & \\ \text { No } & 0 & 0.00 \% & 0 & 0.00 \% & \\ \text { Yes } & 13 & 100.00 \% & 2 & 100.00 \% & \\ \text { No } & 0 & 0.00 \% & 0 & 0.00 \% & \\ \text { Yes } & 6 & 46.15 \% & 0 & 0.00 \% & \\ \text { No } & 7 & 53.85 \% & 2 & 100.00 \% & 0.003 \\ \text { Yes } & 2 & 33.33 \% & 0 & 0.00 \% & \\ \text { No } & 4 & 66.67 \% & 2 & 100.00 \% & 0.102 \\ \text { Yes } & 0 & 0.00 \% & 0 & 0.00 \% & \\ \text { No } & 6 & 100.00 \% & 2 & 100.00 \% & \end{array}$

\begin{tabular}{llllll|} 
Yes & 13 & $43.33 \%$ & 0 & $0.00 \%$ & \\
No & 17 & $56.67 \%$ & 30 & $100.00 \%$ & \\
Yes & 12 & $40.00 \%$ & 0 & $0.00 \%$ & \\
\hline
\end{tabular}

No $18 \quad 60.00 \% \quad 30 \quad 100.00 \%$

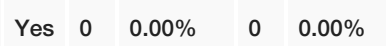

No $30 \quad 100.00 \% \quad 30 \quad 100.00 \%$

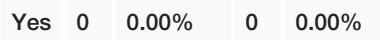

No $30 \quad 100.00 \% \quad 30 \quad 100.00 \%$

$\begin{array}{llll}\text { Yes } 4 & 13.33 \% & 0 & 0.00 \%\end{array}$

0.038

Yes $16 \quad 53.33 \% \quad 5 \quad 16.67 \%$

$\begin{array}{llllll}\text { Yes } & 16 & 53.33 \% & 5 & 16.67 \% & \\ & & & & & 0.003\end{array}$

No $14 \quad 46.67 \% \quad 25 \quad 83.33 \%$

$\begin{array}{lllll}\text { Yes } & 4 & 13.33 \% & 0 & 0.00 \%\end{array}$

0.038

No $26 \quad 86.67 \% \quad 30 \quad 100.00 \%$

$\begin{array}{llllll}\text { Yes } & 6 & 20.00 \% & 0 & 0.00 \% & \\ \text { No } & 24 & 80.00 \% & 30 & 100.00 \% & 0.010 \\ \text { Yes } & 7 & 23.33 \% & 0 & 0.00 \% & \\ \text { No } & 23 & 76.67 \% & 30 & 100.00 \% & 0.005 \\ \text { Yes } & 2 & 6.67 \% & 0 & 0.00 \% & \\ \text { No } & 28 & 93.33 \% & 30 & 100.00 \% & 0.150\end{array}$




\section{Cureus}

\begin{tabular}{|c|c|c|c|c|c|c|}
\hline \multirow{2}{*}{$\begin{array}{l}\text { Did the district supervisor discuss the performance of health facilities based on DHIS information } \\
\text { when he visited your facility? }\end{array}$} & Yes & 6 & $20.00 \%$ & 0 & $0.00 \%$ & \multirow{2}{*}{0.010} \\
\hline & No & 24 & $80.00 \%$ & 30 & $100.00 \%$ & \\
\hline \multirow{2}{*}{ Did the supervisor help you make a decision based on DHIS information? } & Yes & 0 & $0.00 \%$ & 0 & $0.00 \%$ & \multirow{5}{*}{0.150} \\
\hline & No & 30 & $100.00 \%$ & 30 & $100.00 \%$ & \\
\hline \multirow{3}{*}{ Did the supervisor send a report/feedback/note on the last two supervisory visits? } & Yes & 2 & $6.67 \%$ & 0 & $0.00 \%$ & \\
\hline & & & & & & \\
\hline & No & 28 & $93.33 \%$ & 30 & $100.00 \%$ & \\
\hline
\end{tabular}

TABLE 1: Use of Information (Post Intervention)

Upon assessing the OBAT, the staff was more punctual and set targets regularly for them to achieve postintervention. Staff practiced saying no to any decision which was not supported by the evidence or facts and the culture of accepting the mistakes and rectifying it later flourished inside the facilities. The Nowshera staff were more capable and self-efficient in interpreting the data and on the basis of data made graphs and charts to depict the monthly progress of the facility compared to the control district, i.e. Swabi, in the postintervention phase (Table 2).

\begin{tabular}{|c|c|c|c|}
\hline \multirow[t]{2}{*}{ Item } & Nowshera & Swabi & p-value \\
\hline & \multicolumn{2}{|l|}{ Mean Score } & Mann-Whitney-U \\
\hline \multicolumn{4}{|l|}{ In the health department, decisions are based on: } \\
\hline Personal liking & 4.83 & 5.7 & 0.000 \\
\hline Superiors' directives & 6.7 & 5.6 & 0.000 \\
\hline Evidence/facts & 2.17 & 2.03 & 0.502 \\
\hline Political interference & 5.67 & 5.6 & 1.000 \\
\hline Comparing data with strategic health objectives & 1.67 & 2 & 0.112 \\
\hline Health needs & 1.87 & 1.73 & 0.586 \\
\hline Considering costs & 3.43 & 3.23 & 0.469 \\
\hline \multicolumn{4}{|l|}{ In the health department, superiors; } \\
\hline Seek feedback from concerned persons & 1.57 & 1.63 & 0.882 \\
\hline Emphasize data quality in monthly reports & 2.03 & 1.87 & 0.428 \\
\hline Discuss conflicts openly to resolve them & 1.97 & 2.63 & 0.007 \\
\hline Seek feedback from concerned community & 2.03 & 2.43 & 0.157 \\
\hline Use HMIS data for setting targets and monitoring & 2.1 & 1.87 & 0.230 \\
\hline Check data quality at the facility and higher level regularly & 2 & 1.83 & 0.385 \\
\hline Provide regular feedback to their staff through regular report based on evidence & 2.4 & 2.63 & 0.271 \\
\hline Report on data accuracy regularly & 1.93 & 2.4 & 0.141 \\
\hline \multicolumn{4}{|l|}{ In the health department, staff } \\
\hline Are punctual & 1.7 & 2.83 & 0.000 \\
\hline Document their activities and keep records & 2.37 & 1.63 & 0.001 \\
\hline Feel committed to improving the health status of the target population & 2.07 & 1.87 & 0.428 \\
\hline Set appropriate and doable target for their performance & 1.7 & 2.63 & 0.000 \\
\hline Feel guilty for not accomplishing & 2.2 & 2.43 & 0.403 \\
\hline Are rewarded for good work & 2 & 1.87 & 0.387 \\
\hline
\end{tabular}




\section{Cureus}

\begin{tabular}{|c|c|c|c|}
\hline Use HMIS data for day to day management of the facility and district & 1.77 & 1.83 & 0.745 \\
\hline Display data for monitoring their set target & 1.8 & 2.63 & 0.004 \\
\hline Can gather data to find the root cause(s) of the problem & 1.8 & 2.4 & 0.044 \\
\hline Can develop appropriate criteria for selecting interventions for a given problem & 2.33 & 2.63 & 0.359 \\
\hline Can develop appropriate outcomes for a particular intervention & 2.07 & 2.43 & 0.189 \\
\hline Can evaluate whether the targets or outcomes have been achieved & 1.93 & 1.87 & 0.538 \\
\hline Are empowered to make decisions & 2.6 & 1.83 & 0.003 \\
\hline Able to say no to superiors and colleagues for demands/decisions not supported by evidence & 1 & 2.63 & 0.000 \\
\hline Are made accountable for poor performance & 5.97 & 5.53 & 0.056 \\
\hline Use HMIS data for community education and mobilization & 2.3 & 1 & 0.000 \\
\hline Admit mistakes for taking corrective actions & 2.47 & 1 & 0.000 \\
\hline \multicolumn{4}{|l|}{ Personal } \\
\hline Collecting information which is not used for decision making discourages me & 1.93 & 2.63 & 0.005 \\
\hline Collecting information makes me feel bored & 5.97 & 5.83 & 0.637 \\
\hline Collecting information is meaningful for me & 2.2 & 1.4 & 0.001 \\
\hline Collecting information gives me the feeling that data is needed for monitoring facility performance & 2.2 & 2.43 & 0.370 \\
\hline Collecting information gives me the feeling that it is forced on me & 1.9 & 1.63 & 0.213 \\
\hline Collecting information is appreciated by Co-workers and superiors & 2 & 1.67 & 0.114 \\
\hline \multicolumn{4}{|l|}{ Self-Efficacy } \\
\hline I can calculate percentages/rates correctly & 2.33 & 0 & 0.005 \\
\hline I can plot data by months or years & 1.67 & 0 & 0.021 \\
\hline I can compute trend from bar charts & 1.67 & 0 & 0.021 \\
\hline I can explain findings \& their implications & 1.67 & 0 & 0.021 \\
\hline I can use data for identifying gaps and setting targets & 1 & 0 & 0.780 \\
\hline I can use data for making various types of decisions and providing feedback & 1.67 & 0 & 0.210 \\
\hline
\end{tabular}

TABLE 2: Organizational and Behavioral Assessment Tool (OBAT) (Post Intervention)

The quality of data after integration improved as many queries from the PRISM tool package showed significant differences. The process of reporting and meeting the deadlines for the submission of these reports improved post-intervention (Table 3). 


\section{Cureus}

\begin{tabular}{|c|c|c|c|c|c|c|}
\hline \multicolumn{2}{|l|}{ Query } & \multicolumn{2}{|c|}{ Nowshera } & \multicolumn{2}{|c|}{ Swabi } & \multirow[t]{3}{*}{ p-value } \\
\hline \multirow{2}{*}{ Keeping Record } & Yes & 12 & $40.00 \%$ & 12 & $40.00 \%$ & \\
\hline & No & 0 & $0.00 \%$ & 0 & $0.00 \%$ & \\
\hline \multirow{2}{*}{ Number of facilities actually reporting } & Yes & 24 & $80.00 \%$ & 14 & $46.67 \%$ & \multirow{2}{*}{0.007} \\
\hline & No & 6 & $20.00 \%$ & 16 & $53.33 \%$ & \\
\hline \multirow{2}{*}{ Deadline for submission of monthly report } & Yes & 24 & $80.00 \%$ & 14 & $46.67 \%$ & \multirow{2}{*}{0.007} \\
\hline & No & 6 & $20.00 \%$ & 16 & $53.33 \%$ & \\
\hline \multirow{2}{*}{ A Reporting Month A } & Before the deadline & 24 & $80.00 \%$ & 13 & $43.33 \%$ & \multirow{2}{*}{0.003} \\
\hline & After the deadline & 6 & $20.00 \%$ & 17 & $56.67 \%$ & \\
\hline \multirow{2}{*}{ Availability of person for collection of monthly report } & Yes & 24 & $80.00 \%$ & 18 & $60.00 \%$ & \multirow{2}{*}{0.091} \\
\hline & No & 6 & $20.00 \%$ & 12 & $40.00 \%$ & \\
\hline \multirow{2}{*}{ Data Accuracy } & Yes & 14 & $46.67 \%$ & 12 & $40.00 \%$ & \multirow{2}{*}{0.602} \\
\hline & No & 16 & $53.33 \%$ & 18 & $60.00 \%$ & \\
\hline \multirow{2}{*}{ Indicators for Each Facility Catchment Area } & Yes & 10 & $33.33 \%$ & 7 & $23.33 \%$ & \multirow{2}{*}{0.390} \\
\hline & No & 20 & $66.67 \%$ & 23 & $76.67 \%$ & \\
\hline \multirow{2}{*}{ Comparison among Facilities } & Yes & 5 & $16.67 \%$ & 6 & $20.00 \%$ & \multirow{2}{*}{0.739} \\
\hline & No & 25 & $83.33 \%$ & 24 & $80.00 \%$ & \\
\hline \multirow{2}{*}{ Comparison among Type of services } & Yes & 5 & $16.67 \%$ & 7 & $23.33 \%$ & \multirow{2}{*}{0.519} \\
\hline & No & 25 & $83.33 \%$ & 23 & $76.67 \%$ & \\
\hline \multirow{2}{*}{ Is monthly report form complex and difficult to follow } & Yes & 9 & $30.00 \%$ & 20 & $66.67 \%$ & \multirow{2}{*}{0.004} \\
\hline & No & 21 & $70.00 \%$ & 10 & $33.33 \%$ & \\
\hline \multirow{2}{*}{ Do you find that IT is easy to manage? } & Yes & 19 & $63.33 \%$ & 10 & $33.33 \%$ & \multirow{2}{*}{0.020} \\
\hline & No & 11 & $36.67 \%$ & 20 & $66.67 \%$ & \\
\hline \multirow{2}{*}{ DHIS has information that is spread over in different information system } & Yes & 19 & $63.33 \%$ & 16 & $53.33 \%$ & \multirow{2}{*}{0.432} \\
\hline & No & 11 & $36.67 \%$ & 14 & $46.67 \%$ & \\
\hline \multirow{2}{*}{ (LAN) exist to provide access to information to all district managers } & Yes & 11 & $36.67 \%$ & 9 & $30.00 \%$ & \multirow{2}{*}{0.584} \\
\hline & No & 19 & $63.33 \%$ & 21 & $70.00 \%$ & \\
\hline
\end{tabular}

TABLE 3: Quality of Data (Post Intervention)

\section{Discussion}

In Pakistan, adequate and timely information from the District Health Information System (DHIS) is hindered by lack of facility to record the data systematically, lack of feedback system, lack of utilization of knowledge in taking decisions and disease surveillance, inefficient management, power politics, and the incapability of the staff to adapt to the modern system [11-13]. The current study assessed routine health information systems in two districts of Khyber Pakhtunkhwa using a modified conceptual framework, PRISM.

Considering the findings of the current and the previous studies, we can conclude that one of the obstacles in improving the HIS is the poor management of the existing resources. The reasons behind this include poor management of data, low quality of data due to data duplication, selection of data without taking the technicalities into account, lack of proper channel for timely and updated transmission of data to the national level and lack of coordinated efforts to address the problems of the periphery to the district and then to the national level respectively. The health workers do not have access to the proper and standardized training through which they could develop an understanding of the procedure for the collection and 
processing of the data [14]. Furthermore, there is a lack of motivation and financial incentives for the health services workers due to which they tend to lose interest in their work, and chances of errors increase. The lack of a feedback system is another reason behind this low quality of data [13-15].

The current study used a modified PRISM tool to highlight the main issues concerning the DHIS. It was noted that there was no proper management system to ensure the timely transmission of the data from district to provincial and from provincial to the national level. This resulted in outdated, low-quality data, which further affected the decisions made without any sound evidence. Additionally, in many facilities computers were not being used as the staff was not skilled in operating a computer. The utilization of some straightforward and sophisticated programs like GIs, and EPIINFO was also not very popular in the health sector in Pakistan. Similar findings were found in previous studies [16-17].

The research has shown that we lack the management along with the resources. The integration of EPI \& LHW data with the data of HIS in the DHIS software is a positive initiative for upgrading the health information system from the district level. Still, this integration needs a strict follow-up procedure that ensures that the system keeps on working the way they are supposed to do. The HMIS operating in the facilities could be used as the most powerful tool for planning and managing health services. To establish a system that could prove to be efficient enough to respond to the needs of making a decision based upon the information from the healthcare delivery system, we need to have a vast health information system that should have the ability to process all over the country in terms of infrastructure and networking. On a general assessment of the existing health system, it was found out that the overall design is very feeble, the data collection system is not that organized, and information is disseminated in fragments. Because of this situation, efforts should be arranged where the prime focus should be on the organization of data, utilization of the data, and dissemination of the data to the respective stakeholder.

\section{Conclusions}

The current study used the PRISM framework to highlight the main challenges in improving DHIS in Khyber Pakhtunkhwa. It was found that there was no proper management system that ensured the timely transmission of the data from district to provincial and from provincial to the national level. This resulted in outdated, low-quality data which further affected the decisions made without any sound evidence. Additionally, in many facilities computers were not being used as the staff was not skilled in operating a computer. After the integration of EPI and LHW programs, significant improvements in the use of information, data quality, and behavior of staff after the intervention were observed. In short, it is important to properly train the staff on how to operate DHIS in order to gain adequate and timely data on health status and determinants. The integration would benefit in managing the data at not only the national level but at the district level too.

\section{Appendices}




\section{Cureus}

Serial \#

Question

Response

Data Recording

FQ 1 Copy of DHIS monthly reports sent to the district office?

1. Yes

0. No. If no, go to $F Q 5$

FQ 2 \# of DHIS monthly reports kept at the facility for the last 12 months

FQ 3 Does this facility keep an outpatient register?

1. Yes

0. No. If no, go to FQ5

Data Accuracy Check

Find the following information for the two months in the outpatient register

FQ 4

Item

$$
\text { a. Month (specify) }
$$

\# from register

\# from report

b. Month (specify)

\# from register

\# from report

$4 \mathrm{~A}$

4B

4C

$4 \mathrm{D}$

FQ 5 Did you receive a directive from the DHO/DHIS Coordinator to:

5A. Check the data accuracy at least once in three months?

5B. $\quad$ Fill the monthly report form completely

5C. Submit report by due date

1. Yes

0. No

1. Yes

0. No

1. Yes

0. No

FQ 6 Did you receive a directive from the District office that there will be consequences:
6A. If you do not check the data accuracy
1. Yes
0. No
6B. If you do not fill the monthly reporting form completely
1. Yes
0. No
$6 C$
If you do not submit the monthly report by the declared deadline
1. Yes
0. No

Data Completeness

FQ 7 \# of data items in the DHIS monthly report that the facility needs to report?

FQ 8 \# of data items left blank without indicating "0" in the last month's report.

Data Transmission/Data Processing \& Analysis

FQ 9 Do data processing procedures exist?
FQ 10 Does the facility produce the following?
FQ A Indicator of facility catchment area
FQ B Comparisons with district/national targets
FQ C Comparisons among types of services coverage
FQ D $\quad$ Comparisons of data over time (monitoring over time)
FQ $11 \quad$ Does the procedure manual for data collection/definitions exist?

1. Yes

0. No

TABLE 4: DHIS Diagnostic Tool Health Facility Proforma: Quality of Data 


\section{Cureus}

Please rate your confidence in percentages that you can accomplish the HMIS activities. Rate your confidence for each situation with a percentage from the following scale:

Serial \# Item

Scores

SE2. I can calculate percentages/rates correctly

$\begin{array}{lllllllllll}0 & 10 & 20 & 30 & 40 & 50 & 60 & 70 & 80 & 90 & 100\end{array}$

SE3. I can plot data by months or years

$\begin{array}{lllllllllll}0 & 10 & 20 & 30 & 40 & 50 & 60 & 70 & 80 & 90 & 100\end{array}$

SE4. I can compute trend from bar charts

$\begin{array}{lllllllllll}0 & 10 & 20 & 30 & 40 & 50 & 60 & 70 & 80 & 90 & 100\end{array}$

SE5. I can explain findings \& their implications

$\begin{array}{lllllllllll}0 & 10 & 20 & 30 & 40 & 50 & 60 & 70 & 80 & 90 & 100\end{array}$

SE6. I can use data for identifying gaps and setting targets

$\begin{array}{lllllllllll}0 & 10 & 20 & 30 & 40 & 50 & 60 & 70 & 80 & 90 & 100\end{array}$

SE7. I can use data for making various types of decisions and providing feedback

$\begin{array}{lllllllllll}0 & 10 & 20 & 30 & 40 & 50 & 60 & 70 & 80 & 90 & 100\end{array}$

TABLE 5: Self-efficacy Scale

Serial \# Question

In the health department, decisions are based on

D1. Personal liking

D2. Superiors' directives

D3. Evidence/facts

D4. Political interference

D5. Comparing data with strategic health objectives

D6. Health needs

D7. Considering costs

In the health department, superiors

S1. Seek feedback from concerned persons

S2. Emphasize data quality in monthly reports

S3. Discuss conflicts openly to resolve them

S4. Seek feedback from concerned community

S5. Use HMIS data for setting targets and monitoring

S6. Check data quality at the facility and higher level regularly

S7. Provide regular feedback to their staff through regular report based on evidence

S8. Report on data accuracy regularly

In health department, staff

P1. Are punctual

P2. Document their activities and keep records

P3. Feel committed in improving health status of the target population

P4. Set appropriate and doable target of their performance

P5. Feel guilty for not accomplishing the set target/performance

P6. Are rewarded for good work

In health department, staff

P7. Use HMIS data for day to day management of the facility and district 


\section{Cureus}

P8.

Display data for monitoring their set target

P9. Can gather data to find the root cause(s) of the problem

P10. Can develop appropriate criteria for selecting interventions for a given problem

P11. Can develop appropriate outcomes for a particular intervention

P12. Can evaluate whether the targets or outcomes have been achieved

P13. Are empowered to make decisions

P14. Able to say no to superiors and colleagues for demands/decisions not supported by evidence

P15. Are made accountable for poor performance

P16. Use HMIS data for community education and mobilization

P17. Admit mistakes for taking corrective actions

Personal

BC1. Collecting information which is not used for decision making discourages me

BC2. Collecting information makes me feel bored

BC3. Collecting information is meaningful for me

BC4. Collecting information gives me the feeling that data is needed for monitoring facility performance

BC5. Collecting information gives me the feeling that it is forced on me

BC6. Collecting information is appreciated by Co-workers and superiors

TABLE 6: Organizational and Behavioral Assessment Tool (OBAT)

A (Strongly disagree), B (Somewhat Disagree), C (Disagree), D (Neither Agree nor disagree), E (Agree), F (Somewhat agree), G (Strongly agree).

\section{Additional Information \\ Disclosures}

Human subjects: All authors have confirmed that this study did not involve human participants or tissue. Animal subjects: All authors have confirmed that this study did not involve animal subjects or tissue. Conflicts of interest: In compliance with the ICMJE uniform disclosure form, all authors declare the following: Payment/services info: All authors have declared that no financial support was received from any organization for the submitted work. Financial relationships: All authors have declared that they have no financial relationships at present or within the previous three years with any organizations that might have an interest in the submitted work. Other relationships: All authors have declared that there are no other relationships or activities that could appear to have influenced the submitted work.

\section{References}

1. Boerma T, Chopra M, Evans D: Health system performance assessment in the Bulletin . Bull World Health Organ. 2009, 87:2. 10.2471/blt.08.061945

2. Lippeveld T, Sauerborn R, Bodart C: Design and Implementation of Health Information Systems . World Health Organization, Geneva; 2000.

3. Littlejohns P, Wyatt JC, Garvican L: Evaluating computerised health information systems: hard lessons still to be learnt. BMJ. 2003, 326:860. 10.1136/bmj.326.7394.860

4. Furley K, Goldfeld S: The World Health Organization Health Promoting School framework is important for some child health outcomes. J Paediatr Child Health. 2017, 53:194-196. 10.1111/jpc.13475

5. George E, Bailey M, Domigan W: Health monitoring methodology based on exergetic analysis for building mechanical systems. Energy. 2010, 35:1216-1223. 10.1016/j.energy.2009.10.040

6. Aqil A, Lippeveld T, Hozumi D: PRISM framework: a paradigm shift for designing, strengthening and evaluating routine health information systems. Health Policy Planning. 2009, 24:217-228. 10.1093/heapol/czp010

7. Hotchkiss DR, Aqil A, Lippeveld T, Mukooyo E: Evaluation of the performance of routine information system management (PRISM) framework: evidence from Uganda. BMC Health Services Res. 2010, 10:188. 10.1186/1472-6963-10-188

8. Qazi MS, Ali M, Kuroiwa C: The health management information system of Pakistan under devolution: health managers' perceptions. Biosci Trends. 2008, 2:75-80.

9. Shaikh BT, Rabbani F: The district health system: a challenge that remains . East Mediterr Health J. 2004, 


\section{Cureus}

10:208-214.

10. PRISM: performance of routine information system management series. (2020). Accessed: January 10, 2020: https://www.measureevaluation.org/resources/tools/health-information-systems/prism.

11. Pakistan Bureau of Statistics. Khyber Pakhtunkhwa . (2020). Accessed: November 29, 2020: http://www.pbs.gov.pk/pco-kpk-tables.

12. Hafeez A, Mohamud BK, Shiekh MR, Shah SA, Jooma R: Lady health workers programme in Pakistan: challenges, achievements and the way forward. J Pak Med Assoc. 2011, 61:210-215.

13. Khoumbati K, Abbasi M, Shah SG, Stergioulas LK: Integration of public sector healthcare information systems with private sector healthcare providers in Pakistan: challenges, opportunities and solutions. In: Emerging Markets from a Multidisciplinary Perspective. Advances in Theory and Practice of Emerging Markets. Springer, Cham; 2018. 233-240. 10.1007/978-3-319-75013-2_18

14. Alwan A, Ali M, Aly E, et al.: Strengthening national health information systems: challenges and response . East Mediterr Health J. 2016, 22:840-850.

15. Smith M, Madon S, Anifalaje A, Lazarro-Malecela M, Michael E: Integrated health information systems in Tanzania: experience and challenges. Electron J Inf Syst Dev Ctries. 2008, 33:1-21. 10.1002/j.16814835.2008.tb00227.x

16. Khalifa M: Barriers to health information systems and electronic medical records implementation. A field study of Saudi Arabian hospitals. Procedia Comput Sci. 2013, 21:335-342. 10.1016/j.procs.2013.09.044

17. Malik IH, Hameed S: Factors affecting implementation of hospital management information systems in Pakistan. Int J Phys Sci. 2012, 31:2818-2828. 10.5897/IJPS12.193 